\title{
Site Specific Uncertainty in Regional Haze Rule Haze Indexes
}

\author{
Patrick A. Ryan \\ Scottsdale, USA \\ Email: pryan01@cox.net
}

Received July 26, 2011; revised September 24, 2011; accepted October 16, 2011

\begin{abstract}
In 1999, the US Environmental Protection Agency (EPA) published the regional haze rule (RHR). The RHR default implementation plan calls for each class I area $20 \%$ worst baseline (2000-2004) visibility to improve linearly in time to natural conditions in 2064 and in calendar year 2018, each class I area $20 \%$ worst visibility is to comply with the 2018 visibility that falls on the linear improvement glide path from baseline (2000-2004) to natural (2064) conditions. This study shows that accurately assessing compliance depends on assessing the uncertainty in baseline, natural and 2018 visibility estimates. This study identifies $\pm 3 \mathrm{dV}$ and $\pm 4 \mathrm{dV}$ of uncertainty in $20 \%$ worst natural and baseline visibility estimates. The percent uncertainty in calculated 2018 glide path visibility values ranges from $10 \%-45 \%$.
\end{abstract}

Keywords: Haze

\section{Introduction}

The US Environmental Protection Agency (EPA) published the Regional Haze Rule (RHR) [1] in 1999 to protect and improve visibility in national parks and other class I areas. The RHR default implementation plan calls for each class I area 20\% worst baseline (2000-2004) visibility to improve linearly with time reaching natural conditions in 2064. In 2003, the EPA published two guidance documents to provide a default approach regulators can follow to calculate baseline and natural visibility $[2,3]$. A key element of the EPA default method for estimating baseline and natural visibility is to use the Interagency Monitoring of Protected Visual Environments (IMPROVE) model to estimate light extinction.

The IMPROVE model characterizes atmospheric light extinction as caused by light scattering and light absorption by gases and particles. Light scattering and absorption by gases is relatively well-understood. The interaction of light with atmospheric particles is more complex than the interaction of light with gases. Particles are usually a larger contributor to haze than are gases; yet the large variations of particle size and chemical composition in the atmosphere make it difficult to accurately estimate their effects on haze. The IMPROVE light extinction model characterizes particle haze as due to eight aerosol species: ammonium sulfate $\left(\left(\mathrm{NH}_{4}\right)_{2} \mathrm{SO}_{4}\right)$, ammonium nitrate $\left(\mathrm{NH}_{4} \mathrm{NO}_{3}\right)$, organic carbonaceous species $(\mathrm{OCM})$, elemental carbon (EC), species associated with fine soil dust (soil), species contained in course PM (CM, parti- cles with aerodynamic diameters between 2.5 and 10 $\mu \mathrm{m})$, sea salt, and water $\left(\mathrm{H}_{2} \mathrm{O}\right)$.

Using the IMPROVE light extinction model, the EPA method estimates the RHR 2018 linear improving visibility goal as follows. First, using the IMPROVE model each class I area baseline (2000-2004) 20\% worst haze index (HI) is estimated. Second, each class I area $20 \%$ worst natural $\mathrm{HI}$ to be achieved in 2064 is estimated. For baseline and natural visibility values of $24.8 \mathrm{dV}$ and 6.8 $\mathrm{dV}$, the RHR linear improvement goal of achieving natural haze in 2064 equates to $18 \mathrm{dV}(=24.8 \mathrm{dV}-6.8$ $\mathrm{dV})$ improvement over 60 years $(=2064-2004)$ and a calendar year 2018 glide path visibility of $20.6 \mathrm{dV}$ that is a $4.2 \mathrm{dV}$ reduction $(0.3 \mathrm{dV} / \mathrm{yr} \times 14 \mathrm{yr})$ from the baseline level. The following sections present the method and findings of uncertainty in regulator baseline, natural and calendar year 2018 glide path visibility estimates.

\section{Method}

The updated IMPROVE formula [4] for light extinction $\left(b_{\text {ext }}\right)$ calculates haze in units of inverse megameters $\left(\mathrm{Mm}^{-1}\right)$ as the sum of light extinction $\left(b_{\text {ext }}\right)$ from the light scattering by particles $\left(b_{\mathrm{sp}}\right)$, light absorption by particles $\left(b_{a p}\right)$, and light scattering by gases $\left(b_{\mathrm{sg}}\right)$. Light scattering is from $\mathrm{PM}_{2.5}\left(\mathrm{NH}_{4}\right)_{2} \mathrm{SO}_{4}, \mathrm{PM}_{2.5} \mathrm{NH}_{4} \mathrm{NO}_{3}, \mathrm{PM}_{2.5} \mathrm{OCM}$, $\mathrm{PM}_{2.5}$ soil dust, $\mathrm{PM}_{2.5-10}$ mass $(\mathrm{CM})$ and sea-salt. Light absorption is by $\mathrm{PM}_{2.5}$ elemental carbon and Rayleigh scattering is by gases. The IMPROVE light extinction formula is: 


$$
\begin{aligned}
\mathrm{b}_{\text {ext }}= & \mathrm{b}_{\mathrm{sp}}+\left(\mathrm{b}_{\mathrm{ap}}\right)+\mathrm{b}_{\mathrm{sp}} \\
\mathrm{b}_{\mathrm{ext}}= & 2.2 \mathrm{f}_{\mathrm{s}}(\mathrm{RH}) \mathrm{C}_{\left(\mathrm{NH}_{4}\right)_{2} \mathrm{SO}_{4} \text {-Small }} \\
& +4.8 \mathrm{f}_{\mathrm{L}}(\mathrm{RH}) \mathrm{C}_{\left(\mathrm{NH}_{4}\right)_{2} \mathrm{SO}_{4} \text {-Large }} \\
& +2.4 \mathrm{f}_{\mathrm{s}}(\mathrm{RH}) \mathrm{C}_{\mathrm{NH}_{4} \mathrm{NO}_{3} \text {-Small }} \\
& +5.1 \mathrm{f}_{\mathrm{L}}(\mathrm{RH}) \mathrm{C}_{\mathrm{NH}_{4} \mathrm{NO}_{3} \text {-Large }}+2.8 \mathrm{C}_{\mathrm{OCM} \text {-Small }} \\
& +6.1 \mathrm{C}_{\mathrm{OCM} \text {-Large }}+\mathrm{C}_{\mathrm{Soil}}+0.6 \mathrm{C}_{\mathrm{CM}} \\
& +1.7 \mathrm{f}_{\mathrm{ss}}(\mathrm{RH}) \mathrm{C}_{\text {sea-salt }}+\left(10 \mathrm{C}_{\mathrm{EC}}\right)+\mathrm{b}_{\text {Ray }}
\end{aligned}
$$

IMPROVE daily measured aerosol concentrations are substituted for $\mathrm{C}_{\mathrm{i}}$ and represent the daily average ambient concentration of species $\mathrm{i}$. All concentrations are input in $\mu \mathrm{g} / \mathrm{m}^{3}$. The daily RH multipliers $\left(\mathrm{f}_{\mathrm{s}}, \mathrm{f}_{\mathrm{L}}\right.$ and $\left.\mathrm{f}_{\mathrm{ss}}\right)$ account for water absorption by $\left(\mathrm{NH}_{4}\right)_{2} \mathrm{SO}_{4}$ and $\mathrm{NH}_{4} \mathrm{NO}_{3}$ and sea-salt. The IMPROVE formula uses dry light scattering efficiencies for $\left(\mathrm{NH}_{4}\right)_{2} \mathrm{SO}_{4}$ of 2.2 and $4.8 \mathrm{~m}^{2} / \mathrm{g}$, for $\mathrm{NH}_{4} \mathrm{NO}_{3} 2.4$ and $5.1 \mathrm{~m}^{2} / \mathrm{g}$, for OCM 2.8 and $6.1 \mathrm{~m}^{2} / \mathrm{g}$, for soil dust, CM and sea salt used are $1,0.6$ and $1.7 \mathrm{~m}^{2} / \mathrm{g}$, respectively, and the light absorption coefficient used for $\mathrm{EC}$ is $10 \mathrm{~m}^{2} / \mathrm{g}$. $\mathrm{b}_{\text {Ray }}$ is the Rayleigh scattering $(1 / \mathrm{Mm})$, and $\mathrm{C}_{\mathrm{OCM}}$ is estimated as $1.8 \mathrm{C}_{\mathrm{OC}}$.

The RHR states that baseline, natural and 2018 visibility must be estimated in units of deciviews (dV). The conversion of daily light extinction and light scattering estimates in $\mathrm{Mm}^{-1}$ to a daily haze index, HI was calculated using Equation (2a) below. This was followed by statistically averaging the daily $\mathrm{HI}$ values in each tail of the distribution using Equation (2b) to arrive at yearly $20 \%$ best and $20 \%$ worst HI values. The multi-year average baseline (2000-2004) and natural haze 20\% worst HI values were calculated using Formula (2c) below.

$$
\begin{gathered}
\mathrm{HI}_{\mathrm{i}}(\mathrm{dV})=10 \ln \left[\frac{\mathrm{b}_{\text {ext-i }}}{10}\right] \\
\mathrm{HI}_{\mathrm{k}}(\mathrm{dV})=\frac{1}{\mathrm{~N}_{\mathrm{k}}} \sum_{\mathrm{i}=1}^{\mathrm{N}_{\mathrm{k}}} \mathrm{HI}_{\mathrm{i}}(\mathrm{dV}) \\
\mathrm{HI}(\mathrm{dV})=\frac{1}{\mathrm{~N}} \sum_{\mathrm{k}=1}^{\mathrm{N}} \mathrm{HI}_{\mathrm{k}}(\mathrm{dV})
\end{gathered}
$$

$b_{\text {ext-i }}$ is the day $\mathrm{i}$ light scattering nephelometer measurement or IMPROVE model light extinction or light scattering estimate. $\mathrm{HI}_{\mathrm{i}}(\mathrm{dV})$ is the day $\mathrm{i} \mathrm{HI}$ calculated from the nephelometer measurement or IMPROVE model estimate of $b_{\text {ext-i }} \cdot \mathrm{HI}_{\mathrm{k}}(\mathrm{dV})$ is the $20 \%$ best or worst $\mathrm{HI}$ for year $\mathrm{k} . \mathrm{N}_{\mathrm{k}}$ is the number of daily $\mathrm{HI}$ values being averaged to calculate the $20 \%$ best (worst) HI for year k. HI (dV) is the $20 \%$ best or worst $\mathrm{N}$-year average $\mathrm{HI} . \mathrm{N}$ is the number of valid years of $20 \%$ best (worst) HI estimates.

The RHR requires States to analyze the linear rate of light extinction improvement in the 2000-2004 20\% worst HI needed to achieve natural HI conditions by 2064. This linear rate of visibility improvement estab- lishes the calendar year 2018 visibility glide path goal. This 2018 visibility glide path for each class I area is computed using the $20 \%$ worst baseline visibility (20002004 ) and $20 \%$ worst natural visibility estimates within the following formula:

$$
\begin{aligned}
& \mathrm{HI}_{2018}(20 \% \text { Worst Days }) \\
& =\mathrm{HI}_{\text {Baseline }}-\frac{(2018-2004)}{(2064-2004)}\left(\mathrm{HI}_{\text {Baseline }}-\mathrm{HI}_{\text {Natural }}\right)
\end{aligned}
$$

The National Institute of Standards and Technology [5] states it is scientifically impossible to judge the fitness of a calculated value (e.g., 20\% worst HI, or a 2018 progress goal) without assigning a corresponding uncertainty estimate to the value. In this study, the uncertainty associated with the baseline, natural and 2018 visibility estimates was developed by calculating the average difference between IMPROVE model light scattering HI predictions and nephelometer light scattering HI observations:

$$
\Delta=\frac{1}{\mathrm{~N}} \sum_{\mathrm{i}=1}^{\mathrm{N}} \mathrm{HI}_{\mathrm{IMPROVE}-\mathrm{i}}-\mathrm{HI}_{\text {Nephelometer-i }}
$$

The calculated 2018 Progress Goal uncertainty $(\Delta \mathrm{PG})$ depends on baseline and natural haze uncertainty:

$$
\Delta \mathrm{PG}_{2018}=\left(\frac{46}{60}\right) \Delta \mathrm{HI}_{\text {Baseline }}+\left(\frac{14}{60}\right) \Delta \mathrm{HI}_{\text {Natural }}
$$

To estimate the uncertainty in the IMPROVE model light extinction estimates, this study compares IMPROVE daily records of nephelometer (light scattering) measurements with IMPROVE model predictions. IMPROVE model predictions were formed from daily aerosol concentration data and daily RH multipliers by class I site [6]. Actual hourly RH data were used to calculate actual daily $\mathrm{RH}$ multipliers and for comparison regulators assign monthly $\mathrm{RH}$ multipliers for use by class I site in the RHR application. These monthly RH multipliers were downloaded from the VIEWS web site.

\section{Results}

\subsection{IMPROVE Model Aggregate Performance Using Same Day RH Multipliers}

The IMPROVE light extinction model aggregate performance averaged across multiple sites is as follows. A total of 6109 previously compiled and published [7] usable daily average light scattering measurements were compared with same day IMPROVE model predictions. The IMPROVE model predictions were formed from measured daily aerosol concentrations and same day $\mathrm{RH}$ data used to calculate same day $\mathrm{RH}$ multipliers. The daily light scattering daily data and IMPROVE model predicted visibility values were independently sorted in 
ascending order. Table 1 shows the aggregate performance of the IMPROVE model across multiple sites is of significant over prediction $(1.5$ and $2.0 \mathrm{dV})$ of the light scattering measurements from $0-5$ and $5-10 \mathrm{dV}$, a modest $0.3 \mathrm{dV}-0.4 \mathrm{dV}$ of light scattering over prediction from $10-30 \mathrm{dV}$, and a significant $2.1 \mathrm{dV}$ of over prediction of light scattering data above $30 \mathrm{dV}$ (where there are few data points). The purpose of this exercise is to show the IMPROVE model is exceptionally good in the range of $10-30 \mathrm{dV}$ consistent with the authors [4] data fit development of the IMPROVE light extinction model.

\subsection{IMPROVE Model Site-Specific Performance Using Same Day RH Multipliers}

The 6109 daily light scattering visibility values and IMPROVE model light extinction visibility (HI) predictions represent data collected across twenty class I sites [7]. Table 2 identifies the IMPROVE model site-specific performance ranges from $0.9 \mathrm{dV}$ under prediction to 2.0 $\mathrm{dV}$ over prediction of the $20 \%$ best light scattering data $\mathrm{HI}$ values and $1.4 \mathrm{dV}$ of under prediction to $1.2 \mathrm{dV}$ of over prediction of the same site $20 \%$ worst light scattering

Table 1. Aggregate nephelometer and IMPROVE model light scattering (dV) comparisons.

\begin{tabular}{cccc}
\hline \multirow{2}{*}{ Nephelometer Bins } & $\begin{array}{c}\text { Nephelometer } \\
(\mathrm{dV})\end{array}$ & Daily RH & IMPROVE model (dV) \\
\cline { 3 - 4 } $0 \mathrm{dV}-5 \mathrm{dV}$ & 3.3 & 4.3 & 4.8 \\
$5 \mathrm{dV}-10 \mathrm{dV}$ & 7.6 & 8.3 & 9.6 \\
$10 \mathrm{dV}-15 \mathrm{dV}$ & 12.3 & 12.7 & 15.2 \\
$15 \mathrm{dV}-20 \mathrm{dV}$ & 17.2 & 17.5 & 20.3 \\
$20 \mathrm{dV}-30 \mathrm{dV}$ & 23.5 & 23.8 & 26.8 \\
$>30 \mathrm{dV}$ & 31.4 & 33.5 & 35.4 \\
\hline
\end{tabular}

Table 2. Site specific nephelometer and IMPROVE model light scattering HI values.

\begin{tabular}{|c|c|c|c|c|c|c|c|c|}
\hline \multirow{2}{*}{ Site Name } & \multicolumn{4}{|c|}{$20 \%$ Worst HI $(\mathrm{dV})$} & \multicolumn{4}{|c|}{$20 \%$ Best HI (dV) } \\
\hline & IMPROVE & Data & $\Delta$ & $2.0 \Delta$ & IMPROVE & Data & $\Delta$ & $1.5 \Delta$ \\
\hline \multicolumn{9}{|c|}{ Western Sites } \\
\hline Mount Zirkel Wilderness, CO & 11.3 & 12.3 & -1.0 & -2.0 & 4.1 & 3.1 & 1.0 & 1.5 \\
\hline Jarbridge Wilderness, NV & 12.0 & 12.4 & -0.4 & -0.8 & 2.9 & 1.6 & 1.3 & 2.0 \\
\hline Gila WA, NM & 11.8 & 11.9 & -0.1 & -0.2 & 2.8 & 1.7 & 1.1 & 1.6 \\
\hline Three Sisters Wilderness, OR & 16.0 & 16.0 & 0.0 & 0.0 & 6.2 & 5.5 & 0.7 & 1.0 \\
\hline Lone Peak Wilderness, UT & 14.2 & 14.7 & -0.5 & -1.0 & 6.1 & 4.8 & 1.3 & 2.0 \\
\hline Columbia River Gorge, WA & 18.0 & 18.3 & -0.3 & -0.6 & 7.1 & 5.7 & 1.4 & 2.1 \\
\hline Mount Rainier NP, WA & 17.1 & 16.5 & 0.6 & 1.2 & 5.5 & 4.9 & 0.6 & 0.9 \\
\hline Snoqualamie Pass, WA & 16.1 & 17.0 & -0.9 & -1.8 & 6.9 & 6.0 & 0.9 & 1.5 \\
\hline \multicolumn{9}{|c|}{ Central Sites } \\
\hline Boundary Waters, MN & 11.6 & 12.1 & -0.5 & -1.0 & 5.7 & 4.9 & 0.8 & 1.2 \\
\hline Big Bend NP, TX & 16.9 & 17.1 & -0.2 & -0.4 & 5.8 & 5.3 & 0.5 & 0.8 \\
\hline \multicolumn{9}{|c|}{ Northeast Sites } \\
\hline Acadia NP, ME & 19.2 & 18.6 & 0.6 & 1.2 & 6.9 & 6.0 & 0.9 & 1.4 \\
\hline Great Gulf Wilderness, NH & 18.7 & 18.5 & 0.2 & 0.4 & 5.9 & 4.9 & 1.0 & 1.5 \\
\hline Lye Brook Wilderness, VT & 21.4 & 22.0 & -0.6 & -1.2 & 5.9 & 6.8 & -0.9 & -1.4 \\
\hline \multicolumn{9}{|c|}{ Southeast Sites } \\
\hline Upper Buffalo Wilderness, AR & 24.8 & 24.9 & -0.1 & -0.2 & 8.9 & 8.5 & 0.4 & 0.6 \\
\hline Okefenokee Nat'l Refuge, GA & 20.3 & 21.0 & -0.7 & -1.4 & 12.5 & 11.9 & 0.6 & 0.9 \\
\hline Mammoth Cave NP, KY & 24.2 & 24.3 & -0.1 & -0.2 & 11.2 & 10.5 & 0.7 & 1.0 \\
\hline Shining Rock Wilderness, NC & 19.4 & 20.8 & -1.4 & -2.8 & 6.0 & 6.4 & -0.4 & -0.6 \\
\hline Great Smoky Mtns. NP, TN & 28.5 & 27.6 & 0.9 & 1.8 & 11.3 & 9.3 & 2.0 & 3.0 \\
\hline Shenandoah National Park, VA & 23.9 & 22.7 & 1.2 & 2.4 & 8.4 & 7.1 & 1.3 & 2.0 \\
\hline Dolly Sods Wilderness, WV & 25.5 & 24.4 & 1.1 & 2.2 & 10.7 & 8.9 & 1.8 & 2.7 \\
\hline Minimum & & & -1.4 & -2.8 & & & -0.9 & -1.4 \\
\hline Maximum & & & 1.2 & 2.4 & & & 2.0 & 3.0 \\
\hline
\end{tabular}


data $\mathrm{HI}$ values. The $1.4 \mathrm{dV}$ of under prediction to $2.0 \mathrm{dV}$ of over prediction ( $\sim \pm 1.7 \mathrm{dV}$ uncertainty) is this study's 1 st tier site-specific uncertainty estimate of regulators RHR visibility estimates.

The 6109 light scattering and IMPROVE model light scattering prediction data points were collected over 11-years. This 11-year data set ranges from 2-time to slightly more than 3-times as many years of data as regulators used to develop baseline (2000-2004) and natural HI estimates. Regulators used at little as 3-years (49 class I sites), 4-years (53 class I sites) and at most 5-years (43 class I sites) of data for making baseline (2000-2004) and natural HI estimates. Less than 5-years of data were used at some sites because of incomplete IMPROVE aerosol concentration daily data for some years.

To establish uncertainty in regulators baseline and natural visibility estimates from using 3 -years to 5 -years of data, this study compiled site-specific 5-year average $20 \%$ worst and $20 \%$ best light scattering HI visibility values and compared them to worst-case IMPROVE light extinction model visibility predictions using 3-years, 4 -years and 5-years of data. Seven sites were found to have enough days ( 35 days minimum) of data by year and at least 5 consecutive years of data to perform this analysis. Table 3 shows the 3-years, 4-years and 5-years IMPROVE model highest visibility over predictions are $3.8,3.3$ and $3.0 \mathrm{dV}$ of 5 -years of site-specific $20 \%$ best nephelometer HI data. The 3-years, 4-years and 5-years IMPROVE model highest visibility over predictions are $3.1,2.6$ and $2.2 \mathrm{dV}$ of 5 -years of $20 \%$ worst nephelometer $\mathrm{HI}$ data. To extrapolate these findings from the 7 -sites with enough data to make this comparison to all 20-sites with data, the 4-years IMPROVE model worst-case $20 \%$ worst and $20 \%$ best baseline HI performance biases (Table 3) of 2.0 and 1.5 times the uncertainty calculated using all site years of data (Table 2) were multiplied by the 20-sites of IMPROVE model multi-year uncertainty estimates. This was done to develop this study's 2nd tier estimate of uncertainty in regulators 3 -years to 5 -years visibility estimates. This 2 nd tier uncertainty estimate ranges from $2.8 \mathrm{dV}$ of under prediction to $3.0 \mathrm{dV}$ of over prediction ( $\sim \pm 3 \mathrm{dV}$ uncertainty) (see Table 2).

\subsection{Regulators Used Monthly RH Multipliers as Input to the IMPROVE Model}

Regulators baseline and natural visibility estimates use the IMPROVE model with monthly RH multipliers whereas same day RH multipliers were used to develop and validate the IMPROVE model [4] (see Sections 3.1 and 3.2). To assess whether the regulators use of monthly RH multipliers impacts uncertainty in visibility estimates, the following analyses were undertaken.

Table 1 identifies that this study finds the IMPROVE model using regulators assigned monthly RH multipliers consistently over predicts the 6109 daily light scattering measurements. The average over prediction of the IMPROVE model when using monthly RH multipliers is 3 $\mathrm{dV}$ across the visibility range of 10 to $31 \mathrm{dV}$. Figure 1 pictorially shows this finding that the regulators use of monthly RH multipliers (Figure 1, right) causes the IMPROVE model to over predict, by $3 \mathrm{dV}$ on average, 6109 same day light scattering HI readings. Figure 1 also shows the data fitted IMPROVE model using actual same day RH multipliers (Figure 1, left) has no such over prediction issue.

Table 3. Worst site specific years of IMPROVE model light scattering performance.

\begin{tabular}{|c|c|c|c|c|c|c|}
\hline \#Years in $20 \%$ HI statistics & $3-y r$ & $4-\mathrm{yr}$ & $5-\mathrm{yr}$ & $3-\mathrm{yr}$ & $4-\mathrm{yr}$ & 5 -yr \\
\hline \#class I sites & 49 & 53 & 43 & 49 & 53 & 43 \\
\hline \multirow{2}{*}{ Site Name } & \multicolumn{4}{|c|}{$\Delta 20 \%$ Worst HI $(\mathrm{dV})$} & \multicolumn{2}{|c|}{$\Delta 20 \%$ Best HI $(\mathrm{dV})$} \\
\hline & $3-\mathrm{yr}$ & $4-y r$ & $5-\mathrm{yr}$ & $3-\mathrm{yr}$ & $4-y r$ & $5-\mathrm{yr}$ \\
\hline \multicolumn{7}{|c|}{ Western Sites } \\
\hline Mount Zirkel Wilderness, CO & -1.9 & -1.6 & -1.1 & 1.6 & 1.4 & 1.2 \\
\hline Gila WA, NM & -0.9 & -0.8 & -0.4 & 1.6 & 1.4 & 1.3 \\
\hline Lone Peak Wilderness, UT & -1.4 & -1.0 & -0.7 & 2.2 & 1.9 & 1.7 \\
\hline Columbia River Gorge, WA & -1.8 & -1.5 & -0.8 & 2.1 & 2.0 & 1.9 \\
\hline \multicolumn{7}{|c|}{ Central Sites } \\
\hline Big Bend NP, TX & -1.3 & -1.0 & -0.9 & 1.9 & 1.6 & 1.4 \\
\hline \multicolumn{7}{|c|}{ Northeast Sites } \\
\hline Acadia NP, ME & 1.5 & 1.1 & 0.6 & 1.5 & 1.4 & 1.3 \\
\hline \multicolumn{7}{|c|}{ Southeast Sites } \\
\hline Great Smoky Mountains NP, TN & 3.1 & 2.6 & 2.2 & 3.8 & 3.3 & 3.0 \\
\hline Minimum & -1.9 & -1.6 & -1.1 & - & - & - \\
\hline Maximum & 3.1 & 2.6 & 2.2 & 3.8 & 3.3 & 3.0 \\
\hline $\begin{array}{l}\text { Average Site Scale Factor } \\
\Delta \mathrm{HI}(\mathrm{n}-\mathrm{yr}) / \Delta \mathrm{HI}(\text { Table } 2)\end{array}$ & 2.7 & 2.0 & 1.5 & 1.7 & 1.5 & 1.4 \\
\hline
\end{tabular}



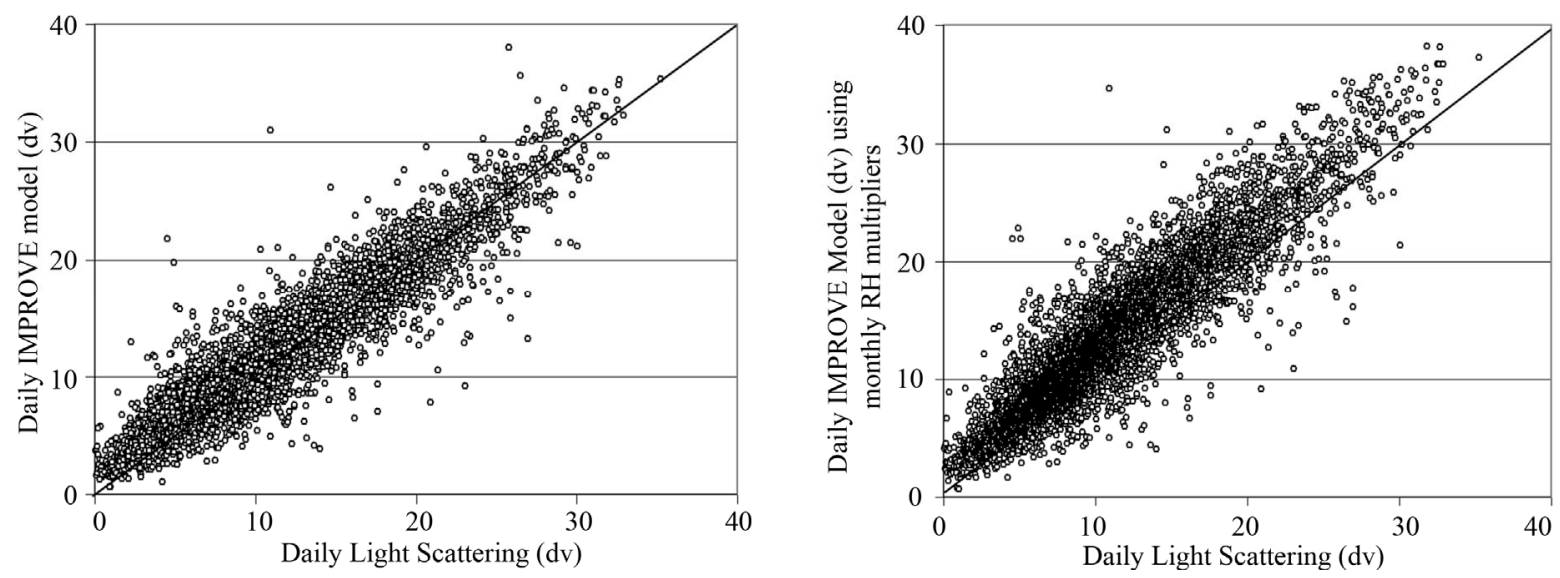

Figure 1. Daily light scattering (dV) compared with IMPROVE model predictions.

The following analysis was conducted to further document this issue. IMPROVE model daily light extinction HI values using both agency designated monthly $\mathrm{RH}$ multipliers and "actual" RH multipliers as input to the IMPROVE model were compared. Columbia River Gorge, WA calendar years 2003 and 2004 and Great Smoky Mountains NP, TN 2000-2004 data were used in this comparison. Each yearly set of daily visibility HI values were sorted, the tails of the distributions averaged, and the yearly $20 \%$ worst and $20 \%$ best visibility values averaged. For Columbia River Gorge, WA, the IMPROVE formula using monthly $\mathrm{RH}$ multipliers $20 \%$ worst baseline $\mathrm{HI}(24.4 \mathrm{dV})$ and $20 \%$ best baseline $\mathrm{HI}(9.2 \mathrm{dV})$ are $1.0 \mathrm{dV}$ and $1.2 \mathrm{dV}$ higher than the validated IMPROVE formula using actual RH multipliers $20 \%$ worst baseline HI $(23.4 \mathrm{dV})$ and $20 \%$ best baseline HI $(8.0 \mathrm{dV})$. For Great Smoky Mountains NP, TN, the IMPROVE formula using monthly RH multipliers $20 \%$ worst baseline $\mathrm{HI}$ $(30.2 \mathrm{dV})$ and $20 \%$ best baseline HI $(13.6 \mathrm{dV})$ are both 1.0 $\mathrm{dV}$ higher than the validated IMPROVE formula using actual RH multipliers 20\% worst baseline HI (29.2 dV) and $20 \%$ best baseline HI ( $12.6 \mathrm{dv})$. Since other sites may show IMPROVE model under prediction and not over prediction, this study assigns a minimum of $\pm 1 \mathrm{dV}$ of uncertainty to the RHR IMPROVE model use of monthly $\mathrm{RH}$ multipliers rather than actual $\mathrm{RH}$ multipliers to develop $20 \%$ worst baseline HI values.

This $\pm 1 \mathrm{dV}$ uncertainty estimate in the IMPROVE model [4] when using monthly RH multipliers instead of daily RH multipliers has limitations. Specifically, the IMPROVE model data fit was constructed using a data set with RH multipliers predominately in the range of values from 1 to 4 . For comparison, the regulators estimate baseline and natural visibility for $1 / 3$ of the class I sites using higher maximum monthly $\mathrm{RH}$ multiplier ranging from 4 to 6.8 . The regulators extrapolation of the IMPROVE model to predict visibility well beyond the RH multipliers used in the data fit adds uncertainty. The amount of uncertainty cannot be quantified, but that does not mean the added uncertainty may not be significant. For example, this study's data set contains only seventeen out of the 6109 days where the daily RH multiplier $\left(f_{s}(R H)\right)$ was above 4 and ranged in value from 4 to 4.7 , and the IMPROVE formula on these days using actual RH multipliers averaged $17.8 \mathrm{dV}$ of visibility that over predicts by $1.2 \mathrm{dV}$ (on average) the nephelometer readings $\mathrm{HI}$ average for these days of $16.6 \mathrm{dV}$.

\subsection{Uncertainty in Regulators RHR HI Estimates}

Regulators have formed RHR 20\% worst baseline and the $20 \%$ worst natural visibility $\mathrm{HI}$ estimates by class I site [6]. The $20 \%$ worst baseline $\mathrm{HI}$ values range from $9.6-31 \mathrm{dV}$. The $20 \%$ worst natural HI values range from $5.6-16 \mathrm{dV}$. This study assigns $\pm 4 \mathrm{dV}$ uncertainty to regulators RHR 20\% worst baseline HI estimates and \pm 3 $\mathrm{dV}$ uncertainty to $20 \%$ worst natural $\mathrm{HI}$ estimates. The $\pm 3 \mathrm{dV}$ of uncertainty is assigned because regulators 3years to 5-years $20 \%$ worst baseline and natural HI uncertainties when using actual RH multipliers are this uncertain compared to 5-years of site-specific 20\% worst nephew-lometer visibility values (see Table 2). This study adds an additional $\pm 1 \mathrm{dV}$ of uncertainty to the $20 \%$ worst baseline visibility estimates because of added uncertainty from regulators use of monthly rather than actual RH multipliers (see Section 3.3).

Table 4 lists for thirty-seven class I sites, this study's $20 \%$ worst baseline, natural and 2018 glide slope HI estimates (which are basically the same as reported by the regulatory agencies [6]). Table 4 also lists this study's assigned $\pm 4 \mathrm{dV}$ baseline and $\pm 3 \mathrm{dV}$ natural HI uncertainty estimates and calculated $\pm 3.8 \mathrm{dV} 2018$ glide slope uncertainty estimate. The percent uncertainty in regulators $20 \%$ worst baseline and natural $\mathrm{HI}$ values ranges from $10 \%$ to $40 \%$ and from $20 \%$ to $50 \%$, respectively. The percent uncertainty in regulators RHR 2018 glide slope visibility estimates ranges from $10 \%$ to $45 \%$. These HI percent uncertainty ranges result in both sites with 
Table 4. IMPROVE equation $20 \%$ worst baseline, progress goal, natural HI statistics.

\begin{tabular}{|c|c|c|c|}
\hline \multirow{2}{*}{ Site Name } & $2000-2004$ & Progress Goal & Natural Haze \\
\hline & $\mu(\mathrm{dV}) \pm$ Unc. $(\mathrm{dV})$ & $\mu(\mathrm{dV}) \pm$ Unc. $(\mathrm{dV})$ & $\mu(\mathrm{dV}) \pm$ Unc. $(\mathrm{dV})$ \\
\hline \multicolumn{4}{|c|}{ Western sites } \\
\hline Denali NP, AK & $10.1 \pm 4$ & $9.4 \pm 3.8$ & $7.4 \pm 3$ \\
\hline Mount Baldy WA, AZ & $11.9 \pm 4$ & $10.5 \pm 3.8$ & $6.6 \pm 3$ \\
\hline Chiricahua NM WA, AZ & $13.5 \pm 4$ & $12.0 \pm 3.8$ & $7.3 \pm 3$ \\
\hline Grand Canyon NP, AZ & $11.8 \pm 4$ & $10.7 \pm 3.8$ & $7.2 \pm 3$ \\
\hline Agua Tibia WA, CA & $23.6 \pm 4$ & $19.7 \pm 3.8$ & $7.7 \pm 3$ \\
\hline Bliss SP, CA & $13.0 \pm 4$ & $11.4 \pm 3.8$ & $6.3 \pm 3$ \\
\hline Death Valley, CA & $15.4 \pm 4$ & $13.7 \pm 3.8$ & $8.0 \pm 3$ \\
\hline Dome Land WA, CA & $19.5 \pm 4$ & $16.6 \pm 3.8$ & $7.6 \pm 3$ \\
\hline Great Sand Dunes NP, CO & $12.9 \pm 4$ & $11.3 \pm 3.8$ & $6.8 \pm 3$ \\
\hline Haleakala NP, HI & $13.4 \pm 4$ & $11.9 \pm 3.8$ & $7.6 \pm 3$ \\
\hline Hawaii Volcanoes NP, HI & $19.0 \pm 4$ & $16.2 \pm 3.8$ & $7.5 \pm 3$ \\
\hline Craters of the Moon NM, ID & $14.1 \pm 4$ & $12.4 \pm 3.8$ & $7.8 \pm 3$ \\
\hline Cabinet Mountains, MT & $14.2 \pm 4$ & $12.5 \pm 3.8$ & $7.8 \pm 3$ \\
\hline Gates of the Mountain, MT & $11.5 \pm 4$ & $10.2 \pm 3.8$ & $6.5 \pm 3$ \\
\hline Glacier NP, MT & $20.5 \pm 4$ & $17.8 \pm 3.8$ & $9.2 \pm 3$ \\
\hline Great Basin NP, NV & $10.4 \pm 4$ & $9.4 \pm 3.8$ & $6.5 \pm 3$ \\
\hline Bandelier WA, NM & $12.5 \pm 4$ & $11.0 \pm 3.8$ & $6.6 \pm 3$ \\
\hline Bosque del Apache, NM & $13.7 \pm 4$ & $11.9 \pm 3.8$ & $6.7 \pm 3$ \\
\hline Hells Canyon, OR & $18.8 \pm 4$ & $16.3 \pm 3.8$ & $8.5 \pm 3$ \\
\hline Bryce Canyon NP, UT & $11.8 \pm 4$ & $10.7 \pm 3.8$ & $7.1 \pm 3$ \\
\hline Canyonlands NP, UT & $11.2 \pm 4$ & $10.0 \pm 3.8$ & $6.6 \pm 3$ \\
\hline Columbia Gorge, WA & $22.8 \pm 4$ & $19.6 \pm 3.8$ & $9.9 \pm 3$ \\
\hline Bridger Wilderness, WY & $11.2 \pm 4$ & $10.0 \pm 3.8$ & $6.7 \pm 3$ \\
\hline \multicolumn{4}{|c|}{ Central sites } \\
\hline Bondville, IL & $29.6 \pm 4$ & $25.3 \pm 3.8$ & $11.4 \pm 3$ \\
\hline Hercules-Glades, MO & $26.9 \pm 4$ & $23.3 \pm 3.8$ & $11.3 \pm 3$ \\
\hline Badlands NP, SD & $17.2 \pm 4$ & $15.1 \pm 3.8$ & $8.2 \pm 3$ \\
\hline Guadalupe Mountains NP, TX & $17.0 \pm 4$ & $14.4 \pm 3.8$ & $6.6 \pm 3$ \\
\hline \multicolumn{4}{|c|}{ Northeast sites } \\
\hline Cape Cod, MA & $25.8 \pm 4$ & $22.9 \pm 3.8$ & $13.3 \pm 3$ \\
\hline Bridgton, ME & $24.0 \pm 4$ & $21.3 \pm 3.8$ & $12.3 \pm 3$ \\
\hline Casco Bay, ME & $25.8 \pm 4$ & $22.9 \pm 3.8$ & $13.3 \pm 3$ \\
\hline Brigantine WA, NJ & $29.2 \pm 4$ & $25.2 \pm 3.8$ & $12.3 \pm 3$ \\
\hline Addison Pinnacle, NY & $28.4 \pm 4$ & $24.5 \pm 3.8$ & $11.6 \pm 3$ \\
\hline Connecticut Hill, NY & $27.8 \pm 4$ & $24.0 \pm 3.8$ & $11.6 \pm 3$ \\
\hline \multicolumn{4}{|c|}{ Southeast sites } \\
\hline Arendtsville, AL & $30.8 \pm 4$ & $26.4 \pm 3.8$ & $11.8 \pm 3$ \\
\hline Caney Creek, AR & $26.5 \pm 4$ & $23.1 \pm 3.8$ & $11.7 \pm 3$ \\
\hline Everglades NP, FL & $22.4 \pm 4$ & $20.0 \pm 3.8$ & $12.1 \pm 3$ \\
\hline Cadiz, KY & $29.6 \pm 4$ & $25.2 \pm 3.8$ & $10.9 \pm 3$ \\
\hline
\end{tabular}

NM-National Monument; NP_-National Park; WA—Wilderness Area.

relatively accurate and inaccurate $\mathrm{HI}$ estimates illustrated as follows. Denali National Park, AK (Denali) is among the cleanest $20 \%$ worst HI sites. Denali $20 \%$ worst baseline and natural $\mathrm{HI}$ statistics are $10.1 \pm 4 \mathrm{dV}$ and $7.4 \pm 3$ $\mathrm{dV}$, respectively, resulting in $\mathrm{HI}$ uncertainties of $40 \%$ and 43\%. Brigantine Wilderness Area (WA), NJ (Brigantine) is among the dirtiest 20\% worst HI sites. Brigantine 20\% worst baseline and natural $\mathrm{HI}$ statistics are $29.2 \pm 4 \mathrm{dV}$ and $12.3 \pm 3 \mathrm{dV}$, respectively, resulting in HI uncertainties of $14 \%$ and $24 \%$ uncertain. For Bondville, IL, the 2018 glide slope visibility is $25.3 \mathrm{dV} \pm 3.8 \mathrm{dV}$ or $15 \%$ uncertain. For
Bridger Wilderness, WY, the 2018 glide slope visibility is $10.1 \mathrm{dV} \pm 3.8 \mathrm{dV}$ or $38 \%$ uncertain.

\section{Conclusions}

Regulators comply with the EPA RHR requirements by calculating $20 \%$ worst baseline and natural visibility values by class I site. The baseline and natural visibility estimates are then used to calculate the calendar year 2018 glide slope visibility. Cornerstones of the regulators baseline, natural and 2018 visibility calculations that 
were evaluated for uncertainty were 1) the IMPROVE light extinction model, 2) assigned monthly RH multipliers, and 3) use of between 3-years to 5-years of calendar year 2000-2004 data.

This study finds the regulators use of the IMPROVE model with monthly RH multipliers and 3-years to 5years of data creates uncertainty in baseline and natural visibility values equal to $\pm 4 \mathrm{dV}$ and $\pm 3 \mathrm{dV}$, respectively. The percent uncertainty this causes in regulators $20 \%$ worst baseline and natural $\mathrm{HI}$ values ranges from $10 \%$ $40 \%$ and $20 \%-50 \%$, respectively. The corresponding uncertainty in regulators 2018 glide slope visibility values ranges from $10 \%-45 \%$.

Other uncertainties in regulators visibility values were identified and are: 1) the IMPROVE model uses monthly RH multipliers that produce visibility values that average $\sim 3 \mathrm{dV}$ higher than the nephelometer data, and 2) the IMPROVE model is extrapolated for use at $\sim 1 / 3$ of the regulated class I sites using monthly RH multiplier values above the effective upper limit of RH multiplier values used in the IMPROVE model data fit. Still other sources of visibility uncertainty exist not discussed in this paper. These other uncertainties include the fact that regulators natural visibility estimates assume two sets of uniform background concentrations of $\mathrm{PM}_{2.5}\left(\mathrm{NH}_{4}\right)_{2} \mathrm{SO}_{4}$, $\mathrm{PM}_{2.5} \mathrm{NH}_{4} \mathrm{NO}_{3}, \mathrm{PM}_{2.5}$ OCM, $\mathrm{PM}_{2.5}$ soil dust, $\mathrm{PM}_{2.5-10}$ mass $(\mathrm{CM})$ that apply across the entire western and separately across the entire eastern United States. The assumed uniform west and east background concentrations ignore large predicted spatial concentration variability [8] and omit the large transboundary contribution of other country emissions to haze in the United States [8,9].

\section{REFERENCES}

[1] US Environmental Protection Agency, "Regional Haze Rule, 40 CFR Part 51, Regional Haze Regulations," Final
Rule, 1 July 1999.

[2] US Environmental Protection Agency, "Guidance for Estimating Natural Visibility Conditions under the Regional Haze Program," EPA-444/B-03-005, September 2003.

[3] US Environmental Protection Agency, "Draft Guidance for Tracking Progress under the Regional Haze Rule," EPA-444/B-03-004, September 2003.

[4] M. Pitchford, W. Malm, B. Schichtel, N. Kumar, D. Lowenthal and J. Hand, "Revised Algorithm for Estimating Light Extinction from IMPROVE Particle Speciation Data," Journal of the Air \& Waste Management Association, Vol. 57, 2007, pp. 1326-1336. doi:10.3155/1047-3289.57.11.1326

[5] National Institute of Science and Technology, "e-Handbook of Statistical Methods," 5 July 2010. http://www.itl.nist.gov/div898/handbook/

[6] IMPROVE, "IMPROVE Data,” 2 July 2010. ftp://vista.cira.colostate.edu/Public/AirQuality/Data/Aero sol/IMPROVE/EntireDataset/

[7] P. A. Ryan, D. Lowenthal and N. Kumar, "Improved Light Extinction Reconstruction in Interagency Monitoring of Protected Visual Environments," Journal of the Air \& Waste Management Association, Vol. 55, 2005, pp. 1751-1759.

[8] J. Rokjin, D. Jacoba, N. Kumar and R. Yantoscaa, "Regional Visibility Statistics in the United States: Natural and Transboundary Pollution Influences, and Implications for the Regional Haze Rule," Atmospheric Environment, Vol. 40, No. 28, 2006, pp. 5405-5423.

doi:10.1016/j.atmosenv.2006.04.059

[9] C. Heald, D. Jacob, R. Park, B. Alexander, T. Fairlie, R. Yantosca and D. Chu, "Transpacific Transport of Asian Anthropogenic Aerosols and Its Impact on Surface Air Quality in the United States," Journal of Geophysical Research, Vol. 111, 2007, Article ID: D14310. 